\title{
Caudate-induced inhibition of hypothalamic attack behavior*
}

\author{
SHELDON I. PLUMER \\ Idaho State University, Pocatello, Idaho 83201 \\ and \\ JEROME SIEGEL \\ University of Delaware, Newark, Delaware 19711
}

\begin{abstract}
Low-frequency caudate stimulation in four cats inhibited the somatic motor directed components of hypothalamic aggression. The autonomic and reflexive aspects of attack were unaffected by the synchronogenic stimulation. These results, in conjunction with previous findings on caudate inhibition, indicate that low-frequency caudate activation interferes with elaboration of goal-directed behavior.
\end{abstract}

Previously, the caudate nucleus was found to be part of a system which modulated the ascending reticular activating system (Buchwald, Wyers, Lauprecht, \& Heuser, 1961; Heuser, Buchwald, \& Wyers, 1961). Electrical stimulation of the caudate nucleus influenced the arousal level of cats. High-frequency stimulation (over $30 \mathrm{pps}$ ) caused behavioral activation, while low-frequency stimulation (0.2-10 pps) induced a state of general inhibition and eventually caused sleep (Buchwald, Wyers, Lauprecht, \& Heuser, 1961). Recently, the inhibitory consequences of low-frequency caudate stimulation have been observed in a variety of instrumental conditioning situations. Rather than producing a state of general inhibition, caudate activation was found to have strong inhibitory influences on tasks which were complex, recently, or incompletely learned. Simple and overlearned reactions were much less susceptible to being inhibited (Buchwald \& Hull, 1967; Buser, Rougeul, \& Perret, 1964; Kitsikis \& Rougeul, 1968; Peeke \& Herz, 1971; Wyers, Peeke, Williston, \& Herz, 1968). Many instrumentally conditioned behaviors have been investigated during the application of low-frequency caudate stimulation. However, there has not been a systematic investigation of behaviors which are automatic in nature and do not depend upon learning.

The purpose of the present study was to determine if synchronogenic caudate stimulation would also have inhibitory influences on innately organized patterns of behavior. Hypothalamic stimulation was used to elicit affective and stalking attack reactions. These behaviors were similar if not the same as those elicited by naturally occurring stimuli (Wasman \& Flynn, 1962; Levison \& Flynn, 1965) and appeared to be innately organized (Roberts \& Bergquist, 1968). The inhibition of these well-controlled intense reactions would allow a severe test of the influence of low-frequency caudate stimulation. Siegel.

\section{METHOD}

Subjects

Four adult female cats were used.

\section{Apparatus}

The apparatus consisted of a $61 \times 61 \times 61 \mathrm{~cm}$ sound-attenuating, electrically shielded, ventilated Industrial Acoustic chamber equipped with a large one-way mirror. Grass SD-5 stimulators and constant-current units were used for all brain stimulation. Cortical activity was recorded on a Grass Model III D polygraph.

\section{Procedure}

Using the stereotaxic coordinates reported by Wasman and Flynn (1962) for attack behavior, multipolar stainless steel wire electrodes. were unilaterally implanted in the hypothalamus of each cat. Hypothalamic sites stimulated to produce attack behavior received biphasic pulses of $1.0 \mathrm{msec}$ duration, $62.5 \mathrm{pps}$, $0.085-0.25 \mathrm{~mA}$

According to coordinates from the Jasper and Ajmone-Marsan (1954) atlas of the cat brain, 24-ga concentric stainless steel electrodes were implanted in the head of the caudate nucleus. Stainless steel screws were used to record cortical activity from the anterior sigmoid gyrus.

Only those cats were used in which caudate electrodes produced the "caudate spindle" (Buchwald, Wyers, Lauprecht, \& Heuser, 1961) to 1-pps trains of $1.0-\mathrm{msec}$ pulses. Preliminary to the study, the cats were trained to make a barpressing response. Intensity values of low-frequency caudate stimulation (6 pps) were found that completely inhibited performance of the operant response. The same type of inhibition was induced as has been observed in previous studies (Buchwald, Horvath, Soltysik, \& Romero-Sierra, 1964; Buser et al, 1964).

In the present experiment, parameters of stimulation to the caudate nucleus were set at those values which-produced complete inhibition of the barpressing operant. Anesthetized rats were placed in the chamber with the cats to serve as attack objects (Levison \& Flynn, 1965). An experimental trial consisted of alternating trials of hypothalamic stimulation alone (control trials) and the same hypothalamic stimulation during low-frequency caudate stimulation (test trials). On test trials, the synchronogenic stimulation was turned on $20 \mathrm{sec}$ prior to the initiation of hypothalamic stimulation. The cat received both stimulus trains until either the hypothalamically induced behavioral reaction occurred or $30 \mathrm{sec}$ elapsed without any attack reaction. 
Table 1

Number of Trials and Percentages of Somatic Motor Attack During Hypothalamic Stimulation Alone and During Combined Hypothalamic and Caudate Stimulation

\begin{tabular}{ccccc}
\hline $\begin{array}{c}\text { Cat Identi- } \\
\text { fication } \\
\text { Number }\end{array}$ & $\begin{array}{c}\text { Hypothalamic } \\
\text { Stimulation } \\
\text { Alone }\end{array}$ & $\begin{array}{c}\text { Hypothalamic } \\
\text { and Caudate } \\
\text { Stimulation }\end{array}$ \\
\hline CD-33 & $20 / 20$ & $(100 \%)$ & $5 / 20$ & $(25 \%)$ \\
CD-40 & $10 / 10$ & $(100 \%)$ & $1 / 10$ & $(10 \%)$ \\
CD-43 & $15 / 15$ & $(100 \%)$ & $1 / 13$ & $(8 \%)$ \\
CD-48 & $10 / 10$ & $(100 \%)$ & $0 / 10$ & $(0 \%)$ \\
Totals & & $100 \%$ & & $11 \%$ \\
\hline
\end{tabular}

\section{RESULTS}

Unilateral hypothalamic stimulation in four cats elicited either the affective or stalking attack reactions as described by Wasman and Flynn (1962). These two forms of attack behavior included integrated patterns of autonomic and somatic motor responses. Bilateral caudate stimulation which had completely inhibited the barpressing operant also inhibited the directed somatic motor components of attack, but did not affect the autonomic and nondirected aspects of the attack. Table 1 shows, for each animal, the percentage of attack behavior which occurred on control trials and on test trials. On an average of $89 \%$ of the test trials, the cats did not initiate the attack, compared to the control trials on which attack was elicited $100 \%$ of the time. Those cats in which an affective attack had been induced displayed the same autonomic reactions as on the control trials. There was pupil dilation, piloerection, extended claws. rapid and deep respiration, hissing, growling, arching of the back, and flattening and retraction of the ears. However, instead of using their claws to attack the rats, these cats exhibited a nondirected emotional discharge which consisted of slashing and pouncing at the air in front of them.

Caudate stimulation was delivered to cats which had previously displayed a stalking form of attack behavior. As on the control trials, with initiation of the hypothalamic stimulation, the cats circled the chamber and began the stalking phase of the attack. But, instead of initiating a vicious biting attack towards the neck of the rat, the cats ignored the rat, often stepping on and over it without making any attempt to attack it. Although piloerection and the other signs of sympathetic arousal were not as intense as during affective attack. they were still unaffected by caudate stimulation.

On an average of $11 \%$ of the test trials in which attacks did occur. they were initiated with a latency $10-15 \mathrm{sec}$ longer than on control trials (latency less than $10 \mathrm{sec}$ ) and were very brief compared to attacks which occurred on the control trials. In all cats, only the well-integrated and goal-directed somatic motor behaviors were inhibited by caudate stimulation. The nondirected and diffuse somatic and autonomic reactions were unaffected. The caudate stimulation was never observed to produce any motor manifestations or competing responses. The animals appeared capable of making the attack reactions, but lacked the ability to direct them in an appropriate manner.

At the conclusion of the experiment, electrode placements were rerified histologically using frozen sections (Siegel, 1968). The electrodes were positioned in the appropriate areas of the hypothalamus (Wasman \& Flynn, 1962) and the caudate nucleus (Buchwald et al, 1964; Buchwald, Hull, \& Trachtenberg, 1967).

\section{DISCUSSION}

Low-frequency caudate stimulation (6 pps) appeared to have differential effects on the various somatic and autonomic components of hypothalamically elicited attack behavior. The results showed that on most trials, the directed somatic motor aspects of aggression were completely inhibited, while the concomitant nonspecific autonomic and nondirected somatic aspects of the attack were unaffected. Earlier research found that high-frequency electrical stimulation (62 pps) of the amygdala (Egger \& Flynn, 1967), dorsal hippocampus (Siegel \& Flynn, 1968), cingulate gyrus (Siegel \& Chabora, 1971), and septum (Siegel \& Skog, 1970) induced suppressive effects on all components of hypothalamically elicited attack, and not just on the directed somatic motor aspects. This suppression was reflected in the form of increased latencies to attack. Suggestions were made that the amygdala, dorsal hippocampus, septum, and cingulate gyrus modulated hypothalamic activity, and hence the attack reaction through common limbic system interconnections (Egger \& Flynn, 1967; Siegel \& Flynn, 1968; Siegel \& Chabora, 1971; Siegel \& Skog, 1970).

A few distinctions can be made concerning the inhibition produced by activation of the caudate nucleus compared to that induced by the limbic structures. One distinction would be that the suppression produced by the latter structures was specifically related to the aggressive behavior and appeared to raise the threshold just for that particulai sequence of reactions. While all of the components of the attack were susceptible to the limbic-induced inhibition, there was no indication that the stimulation influenced other behaviors (Egger \& Flynn, 1967; Siegel \& Flynn, 1968; Siegel \& Chabora, 1971: Siegel \& Skog, 1970). On the other hand, caudate activation did more than increase latencies to attack; it actually prevented the occurrence of most attacks. Furthermore, caudate-induced inhibition was not restricted to hypothalamically elicited at tack. In this and previous experiments, caudate stimulation was found to produce inhibitory effects on a variety of behaviors (Buchwald, Wyers, Carlin. \& Farley, 1961; Buser et al. 1964: Kitsikis \& Rougeul, 1968: Peeke \& Herz, 1971: Wyers et al. 1968). Secondly, when stimulation comparable to that delivered to the limbic structures (62 pps) was used to activate the caudate nucleus. behavioral inhibition was not induced. In fact. the 
opposite occurred, and the animals became activated (Buchwald, Wyers, Lauprecht, \& Heuser, 1961). When these points are considered in conjunction with the differential caudate inhibitory effects on directed somatic vs nondirected somatic and autonomic components of attack, it appears that the caudate nucleus is generating a different type of inhibitory influence than that produced by the limbic structures.

Many attempts have been made to determine the mechanism responsible for caudate-induced inhibition. Several investigations have indicated that caudate stimulation interfered with behavior by disrupting memory traces (Herz \& Peeke, 1971; Peeke \& Herz, 1971; Wyers et al, 1968; Wyers \& Deadwyler, 1971). However, this disruption would not explain the inhibition of directed attack behavior, since Roberts and Bergquist (1968) have shown with cats raised in social isolation that hypothalamically elicited attack was innately organized and thus not dependent upon recent memory traces.

The present results indicate that the inhibitory effects of caudate stimulation are not just concerned with the performance of learned responses. Rather, the disruption is probably more general in nature and taking place at some level of motor outflow (Kitsikis \& Rougeul, 1968), since sensory processing and attention appear to be unaffected during caudate stimulation (Buchwald et al, 1964; Buser et al, 1964; Kitsikis \& Rougeul, 1968). Not all motor outflow is affected by caudate stimulation, as seen by its inability to inhibit reactions such as orienting (Buchwald et al, 1964; Buser et al, 1964; Kitsikis \& Rougeul, 1968) and the presently described autonomic and reflexive components of attack behavior. These results are consistent with studies (Buchwald, Wyers, Carlin, \& Farley, 1961; Buchwald et al, 1964; Peeke \& Herz, 1971; Kitsikis \& Rougeul, 1968; Wyers \& Deadwyler, 1971) that report disruption of goal-directed behaviors during caudate stimulation. As the complexity of the task increases, so does the inhibitory influences (Buchwald \& Hull, 1967). Thus, instead of dealing with caudate stimulation as a disrupter of memory processes (Herz \& Peeke, 1971), it may be more fruitful to investigate its interference with motor elaboration of directed, goal-oriented behavior. This conclusion is supported by the finding of Wilburn and Kesner (1972) that caudate stimulation produced inconsistent amnestic effects.

\section{REFERENCES}

Buchwald, N. A., Horvath, F., Soltysik, S., \& Romero-Sierra, C. Inhibitory responses to basal ganglia stimulation. Boletin Institut de Estudios Medicos Biologicos (Mexico), 1964, 22, 363-377.

Buchwald, N. A., \& Hull, C. D. Some problems associated with interpretation of physiological and behavioral responses to stimulation of caudate and thalamic nuclei. Brain Research, 1967, 6, 1-11.

Buchwald, N. A., Hull, C. D., \& Trachtenberg, M. C. Concomitant behavioral and neural inhibition and disinhibition in response to subcortical stimulation Experimental Brain Research, 1967, 4, 58-72.

Buchwald, N. A., Wyers, L. J., Carlin, J., \& Farley, R. E. Effects of caudate stimulation on visual discrimination. Experimental Neurology, 1961, 4, 23-36.

Buchwald, N. A., Wyers, E. J., Lauprecht, C. W., \& Heuser, G. The "caudate-spindle" IV. A behavioral index of caudate-induced inhibition. Electroencephalography \& Clinical Neurophysiology, 1961, 13, 531-537.

Buser, P., Rougeul, A., \& Perret, C. Caudate and thalamic influences on conditioned motor responses in the cat. Boletin Institut de Estudios Medicos Biologicos (Mexico), 1964, 22, 293-307.

Egger, M. D., \& Flynn, J. P. Further studies on the effects of amygdaloid stimulation and ablation on hypothalamically elicited attack behavior in cats. In W. R. Adey and T. Tokizane (Eds.), Structure and function of the limbic system, progress in brain research. Vol. 27. Amsterdam: Elsevier, 1967. Pp. 165-182.

Herz, M. J., \& Peeke, H. V. S. Impairment of extinction with caudate nucleus stimulation. Brain Research, 1971, 33, 519-522.

Heuser, G., Buchwald, N. A., \& Wyers, E. J. The "caudate-spindle" II. Facilitatory and inhibitory caudate-cortical pathways. Electroencephalography \& Clinical Neurophysiology, 1961, 13, 519-524.

Jasper, H. H., \& Ajmone-Marsan, C. A stereotaxic atlas of the diencephalon of the cat. Ottawa: National Research Council of Canada, 1954.

Kitsikis, A., \& Rougeul, A. The effect of caudate stimulation on conditioned motor behavior in monkeys. Physiology \& Behavior, 1968, 3, 831-837.

Levison, P. K., \& Flynn, J. P. The objects attacked by cats during stimulation of the hypothalamus. Animal Behaviour, $1965,13,217-220$.

Peeke, H. V. S., \& Herz, M. J. Caudate nucleus stimulation retroactively impairs complex maze learning in the rat. Science, 1971, 173, 80-82.

Roberts, W. W., \& Bergquist, E. H. Attack elicited by hypothalamic stimulation in cats raised in social isolation. Journal of Comparative \& Physiological Psychology, 1968, 66, 590-595.

Siegel, A., \& Chabora, J. Effects of electrical stimulation of the cingulate gyrus upon attack behavior elicited from the hypothalamus in the cat. Brain Research, 1971, 32, 169-177.

Siegel, A., \& Flynn, J. P. Differential effects of electrical stimulation and lesions of the hippocampus and adjacent regions upon attack behavior in cats. Brain Research, 1968, 7, 252-267.

Siegel, A., \& Skog, D. Effects of electrical stimulation of the septum upon attack behavior elicited from the hypothalamus in the cat. Brain Research, 1970, 23, 371-380.

Siegel, J. A rapid procedure for locating deep electrode placements. Physiology \& Behavior, 1968, 3, 203-204.

Wasman, M., \& Flynn, J. P. Directed attack elicited from hypothalamus. Archives of Neurology, 1962, 6, 220-227.

Wilburn, M. W., \& Kesner, R. P. Differential amnestic effects produced by electrical stimulation of the caudate nucleus and nonspecific thalamic system. Experimental Neurology, 1972, $34,45-50$.

Wyers, E. J., \& Deadwyler, S. A. Duration and nature of retrograde amnesia produced by stimulation of caudate nucleus. Physiology \& Behavior, 1971, 6, 97-103.

Wyers, E. J., Peeke, H. V. S., Williston, J. S., \& Herz, M. J. Retroactive impairment of passive avoidance learning by stimulation of the caudate nucleus. Experimental Neurology, $1968,22,350-366$.

(Received for publication January 29, 1973; revision received April 5, 1973; accepted May 1, 1973.) 